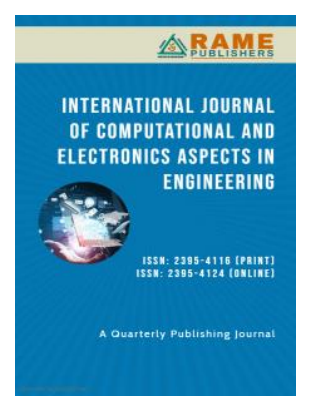

Priya D. Armarkar priya.kumbhalkar@rediffmail.com

Vaishali C. Asole vaishalighormare16022@gmail.com

Samiksha S. Thul samiksha.thul@gmail.com

Department of Computer Engineering, Smt. Radhikatai Pandav College of Engineering, Nagpur, India

\title{
Online Examination System - A Web-Based Application
}

Abstract - Today PHP's online test system has become a rapidly growing test method, due to its speed and accuracy. Less work is also necessary to carry out the test. Nearly all organizations now perform their objective exams online, saves time for exams for students. Organizations can also easily monitor the student's performance during an exam. As a consequence, the results will be released in less time. It also saves paper to help the environment. In php, the online exam paper is very useful to learn according to current requirements. This paper uses a PHP script with Mysql database online test system. So, you are looking for any educational paper or build small PHP systems with the Mysql database, so you're in the right position. Because the solution to your needs can be found in this post. Here we will build a PHP online exam application with the Mysql database to assist you in creating your final year paper for your education. And if you are a PHP programmer beginner and learn how to use any PHP dynamic online system, this article will help.

Keywords - Online examination, PHP script, Mysql database, examination category.

\section{INTRODUCTION}

Test your user identification and password with your card in an online exam system. This id is saved on the test server already. When you check your server login, it already registers its profile. When the examination is done, the message will be sent to begin the exam. All test answers with his/her profile information are saved to the server. The online exam system also enables the examiner to correct the answer if it needs to change any reply over the exam time period, but no change will be possible after the time period. This also makes it easy to check the answer and prove the error as computers are precise and give quick results too. Php is a web-base language that allows us to create a PHP online exam system.

Research Article

First Online on - 10 July 2021

(C) 2021 RAME Publishers

This is an open access article under the CC BY 4.0 International License https://creativecommons.org/licenses/by/4.0/

Cite this article - Priya D. Armarkar, Vaishali C. Asole, Samiksha S. Thul, "Online Examination System - A Web-Based Application", International Journal of Computational and Electronic Aspects in Engineering, RAME Publishers, vol. 2, issue 3, pp. 46-50, 2021. https://doi.org/10.26706/ijceae.2.2.20210414
In the internet world, every task has been done via the internet, which is why we decided not to conduct a review via the internet. This small online examination system paper has been developed for converting the current test system into a digital examination system. This system will automate our existing test system into a digitization examination system if it is built into a professional level. In this system, less workforce is needed for the execution system, and more accurate and less time-consuming, while we can perform more examinations simultaneously and publish results within a very short period. The benefits of the online exam system are available below. Once this system is implemented, the examination will not only be carried out in four classrooms, but students can take part in an examination from any place. The Online Examination Administrator has several features such as adding, deleting, updating and questioning. By logging on using user identification and password provided when registering, the user automatically receives the updated version. No need of reprinting, appearance, vigilance and the job are done.

\section{A. Online examination system features}

- Login system which is secured by password. 
- Explanation of the answer given by the candidate along with the question.

- Answer checking system is available.

- Update Profile

- Log out after the over.

- Admin Panel

\section{B. Objective: Online Examination System in PHP}

The online test system represents a non-removable pattern of contemporary living. We have to save more time and have a more precise exam system as the number of applicants is growing every day. It is important to have some fundamental knowledge of the online examination system for all IT students and professionals. You can obtain the source code of the running paper on this site. It helps you to understand the paper's concept.

C. Brief overview of the technology: Online Examination System in PHP

- Front end: HTML, CSS, JavaScript

1. HTML: HTML is used to create and save web document. e.g., Notepad/Notepad++

2. CSS: (Cascading Style Sheets) Create attractive Layout

3. Bootstrap: responsive design mobile friendly site

4. JavaScript: it is a programming language, commonly use with web browsers.

- $\quad$ Back end: PHP, MySQL

1. PHP: Hypertext Preprocessor (PHP) is a technology that allows software developers to create dynamically generated web pages, in HTML, XML, or other document types, as per client request. PHP is open-source software.

2. MySQL: MySQL is a database, widely used for accessing querying, updating, and managing data in databases.

- Minimum Hardware Requirement

Processor: P-IV $2.20 \mathrm{GHz}$ \& Above

RAM : 512 MB \& Above

Hard-Disk Capacity: 50 GB \& Above

\section{REQUiREMENT ANALYSIS}

The following is a description of the system's subsequent development based on requirement analysis.

- This system is capable of supporting a variety of ways for creating a paper for various exams. The teacher can use the method of making a paper randomly while working in $\mathrm{B} / \mathrm{S}$ mode.

- This system can conduct an accurate, quick examination with virtual paper through the internet/intranet, and it has a variety of capabilities, including database management, automatic paper generation, and examination results, which may cover the entire test procedure.

- $\quad$ Eight different types of systems can be managed and adapted to most testing requirements. Examples of objective subjects are judgement, one choice, multiple choices and cloze. Examples of questions include translation, filling in blanks, and essay questions.

- The database can only be supplemented with new subject types by the administrator, while only test parameters are modified by the teacher. Different users have different and well-defined allowances. If a teacher wants to test a new subject type, he should give the administrator first and then complete the test settings himself.

- The student receives the results of his objective subjects immediately after the paper is submitted. The system will store the subjects, which will be reviewed later by the teacher. By adding the two sections together, the final score is calculated.

This system is simple to expand.

- MySQL, which is one of the most popular databases on the Internet today, is more performing than charging-free. MySQL is considered to be the fastestaccess database, and in other ways MySQL is not less than other commercial databases created by large companies.

- MySQL is more suitable for the construction of a medium system, such as an examination system. 
- PHP works best with MySQL and is also free of charge among all programming languages. Its function increased in power with the release of PHPv8.0. Also, in comparison with other languages PHP is easier to learn. In addition, in Linux and Unix systems, PHP is working well.

- The hardware used here includes the PC servers (including XAMPP, PHP, MySQL and other) as well as an Ethernet network card, a WAN or LAN, and the software used in our system.

- XAMPP stands for multiplatform, Apache, MySQL, PHP, and Perl, which enables you to build offline WordPress sites on the local web server. Server on your computer installed This simple, lightweight solution is Windows, Linux and Mac compatible.

As a result, the "cross-platform" component is included.

\section{SYSTEM IMPLEMENTATION}

The online examination system structure is based on the PHP and the MySQL databases This system used the Web browser as a client, it is very important to ensure that the database is managed and well designed in order to use the server functionality completely. The MySQL database management process is host-dependent. In order to access the system server, each database needs a well-managed user id and password.

The online exam system architecture is illustrated in figure 2 below.

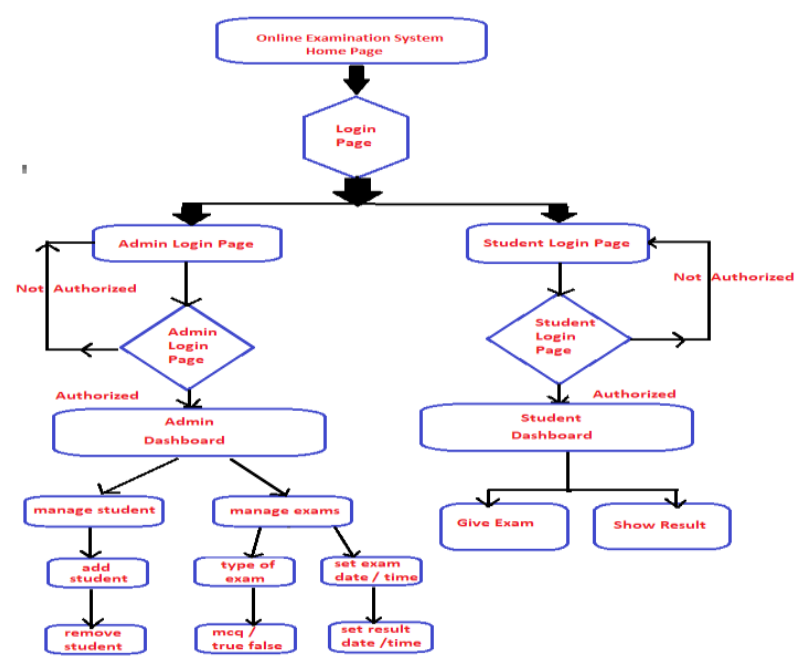

Figure 2: System architecture of online examination system

\section{A. Modules of system}

- $\quad$ Student aspect

All student's information will be saved to a database and visible to the administration panel, which facilitates the examination details per admin. After registration process. Another error will occur whenever you log into the system, if it does not match the database, then login details will be checked in the database. By notification for the next exam, the student shall be notified.

- Student login

- Student dashboard

- Exam module

- Admin module

- $\quad$ Exam Reports etc

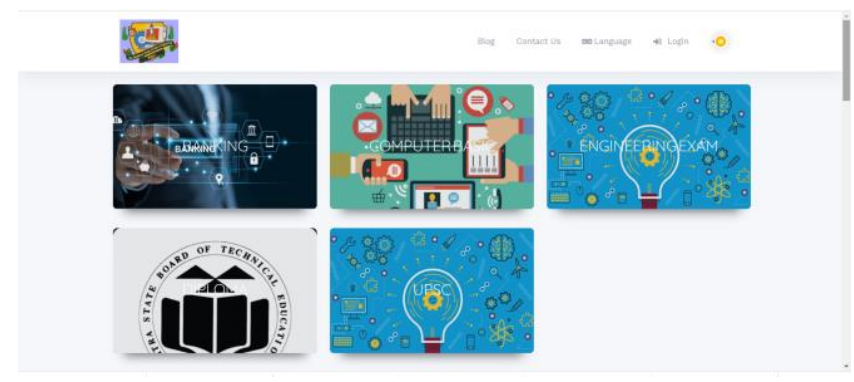

Figure 3: Categories for online examination

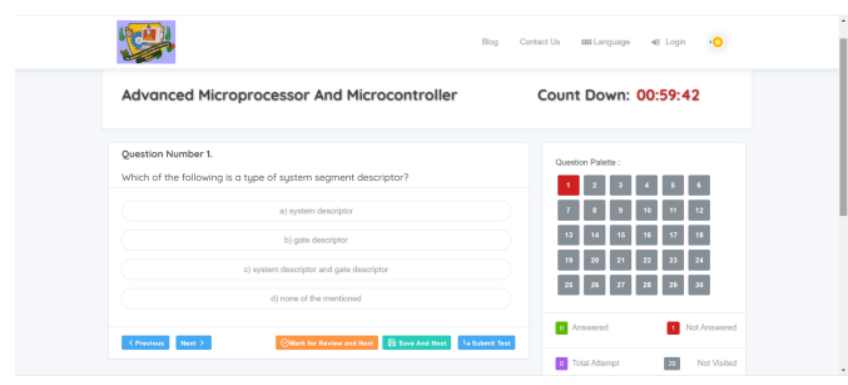

Figure 4: Examination section

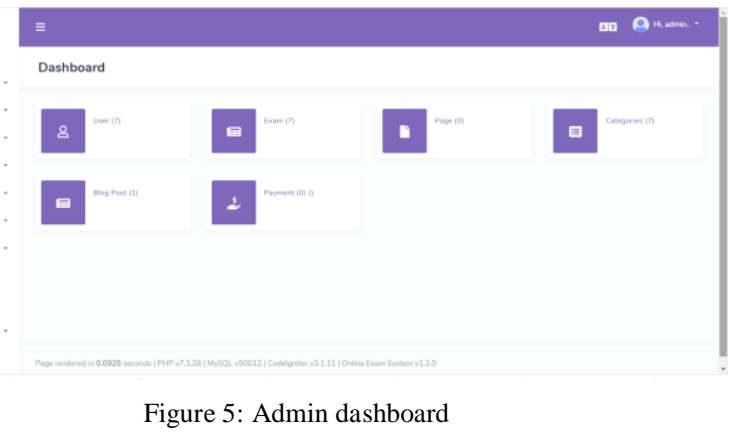




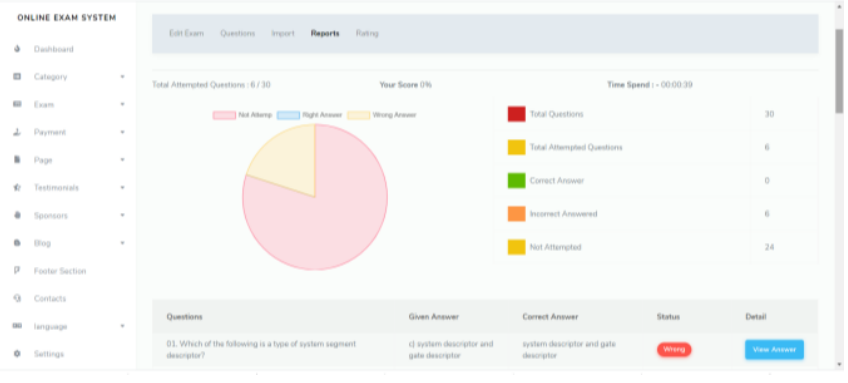

Figure 6: Examination report generation
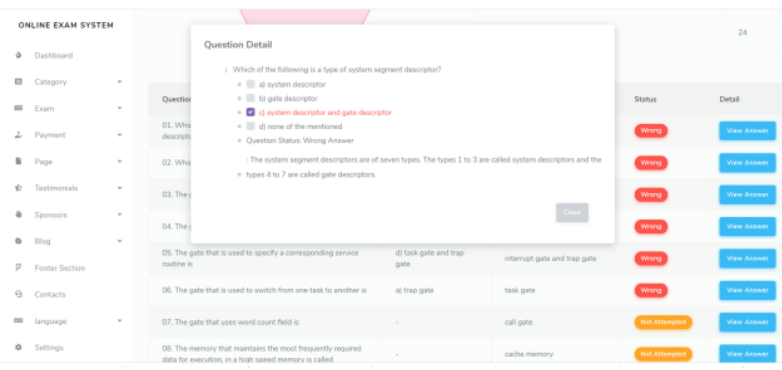

Figure 7: Answer with explanation of objective question

\section{CONCLUSIONS}

A web application is the Online Examination System (OLES). The central conception is to minimize the paper quantity and to digitalize all forms of documentation. It can be observed that the necessary information can be obtained in a computerized system easily and precisely. The system can be easily operated by the user with minimum computer knowledge. The system also generates the management's short results. This article uses the current operation of the online examination to be a model, elaborates the basic knowledge of the online test system based on Java and thoroughly studies the technical requirements necessary for developing the system and finally designs the system and an online exam system based on Java that complies with the requirements of an online examination system.

\section{FUTURE SCOPE}

In comparison with other exams, the online testing system is widely used. Private institutes as well as educational institutions can use the online exam system. It can be used anywhere or anytime because it's a userfriendly web base application. Some bugs, failures, security-related problems or system failures may be present in any software. Many problems or system failures, for instance; a failure of the computer or power failure will render the efforts of many students invalid. In many cases, software can produce incorrect results or display invalid information. For improved software quality, these bugs must be identified and resolved. Thus, by using advanced technologies, we can create safer software in the future.

\section{REFERENCES}

[1] Yang X., "The Research on Online Examination System of PE Theory Courses", In: Du Z. (eds) Proceedings of the 2012 International Conference of Modern Computer Science and Applications. Advances in Intelligent Systems and Computing, vol 191. 2013. Springer, Berlin, Heidelberg. https://doi.org/10.1007/978-3-642-33030-8_58.

[2] Choubey, Anjali and Kumar, Avinash and Behra, Ayush Ranjan and Kisku, Anil Raj and Rabidas, Asha and Bhadra, Beas, "A Study on Web Based Online Examination System" International Conference on Recent Trends in Artificial Intelligence, IOT, Smart Cities \& Applications, 2020. http://dx.doi.org/10.2139/ssrn.3611554.

[3] Muna R. Hameed, Firas. A. Abdullatif, "Online Examination System", International Advanced Research Journal in Science, Engineering and Technology, Vol. 4, Issue 3, March 2017.

[4] Zhang Yong-Sheng; Feng Xiu-Mei; Bao Ai-Qin, "The Research and Design of Online Examination System", International Conference on Information Technology in Medicine and Education (ITME), IEEE Xplore: 10 March 2016.

[5] Neetesh Kumar, Sabeen Gul, Shahbaz Wahab, Mohammad Umer, Arshd Arain, "A web-based online examination system for computer science education”, International Journal of Scientific \& Engineering Research, Volume 9, Issue 7, July-2018.

[6] Kerryn Butler-Henderson, and Joseph Crawford, "A systematic review of online examinations: A pedagogical innovation for scalable authentication and integrity", Computers \& Education, Volume 159, December 2020. doi: 10.1016/j.compedu.2020.104024.

[7] Qiao Fang Zhao, Yong Fei Li, "Research and Development of Online Examination System", Advanced Materials Research, Volumes 756-759, 2013. https://doi.org/10.4028/www.scientific.net/AMR.756759.1110 
[8] Frankl G., Napetschnig S., Schartner P., "Pathways to Successful Online Testing: eExams with the "Secure Exam Environment" (SEE)", Communications in Computer and Information Science, vol 1022, 2019, Springer, Cham. https://doi.org/10.1007/978-3-030-21151-6_12

[9] V. Lalitha, J. K. Periasamy, "Mobile based secured student online exam system", International Journal of Engineering \&
Technology, International Journal of Engineering \&Technology, 7 (1.7) (2018) 118-120.

DOI: 10.14419/ijet.v7i1.7.9588

[10] Rizwana Wahid \& Oveesa Farooq, "Online Exams in the Time of COVID-19: Quality Parameters", International Journal of Social Sciences \& Educational Studies, Vol.7, No.4, December 2020. DOI:10.23918/ijsses.v7i4p13 